chuyển thở máy NIV. Kỹ thuật IPV được bệnh nhân dung nạp tốt. Tuy nhiên, cần phải có nghiên cứu can thiệp ngẫu nhiên ở quy mô lớn hơn để làm rõ vai trò của IPV trong điều trị đợt cấp COPD.

\section{TÀI LIỆ THAM KHẢO}

1. Nguyễn Viết Tiến, Ngô Qúy Châu, Lương Ngoc Khuê (2018) Hướng dẫn chẩn đoán và điêu tri bềnh phổi tắc nghẽn man this. Nhà xuất bản Y hoc.

2. Hogg JC, McDonough JE, Suzuki M (2013). Small Airway Obstruction in COPD. N. Engl. J. Med. $365,1567-1575$

3. Fernandez-Restrepo $L$, Shaffer $L$, Amalakuhan B, Restrepo MI, Peters J, Restrepo R (2017). Effects of intrapulmonary percussive ventilation on airway mucus clearance: A bench model. World J Crit Care Med. 6, 164-171.

4. Osadnik CR, McDonald CF, Holland AE (2013). Advances in airway clearance technologies for chronic obstructive pulmonary disease. Expert Rev Respir Med. 2013;7, 673-685

5. Nguyễn Quang Đợi, Chu Thi Hanh và công sứ (2019) Nghiên cứu đặc điểm lâm sàng, cận lâm sàng và một số yếu tố nguy cơ tắc động mạch phỏi cấp ở bệnh nhân đợt cấp bệnh phổi tắc nghẽn mạn tính. Tạp chí Y học Việt Nam

6. Frédéric Vargas, Hoang Nam Bui, et al (2015). Intrapulmonary percussive ventilation in acute axacerbations of COPD patients with mild respiratory acidosis. A raldomized controlled trial. Critical Care. 382 - 389 - 2005.

7. Nguyễn Thanh Hồi và công sự (2013) Nghiên cứu đắc điểm lâm sàng, x-quang phổi, và kết quả khí máu ở bênh nhân đợt câp bệnh phổi tắc nghẽn man tính tại trung tâm hô hấp - bênh viện Bạch Mai. Tap chí Lao và bệnh phổi (15) 44-49.

8. Nicolini A, Russo D, Grecchi B. (2018) Comparison of Intrapulmonary Percussive Ventilation and High Frequency Chest Wall Oscillation in Patients With Severe Chronic Obstructive Pulmonary Disease. Internationa Journal of COPD, 617-625.

\title{
HIẾU QUẢ THỤ TINH TRONG ỐNG NGHIỆM BẰNG TINH TRÙnG TRÍCH XUẤT TẠI BỆNH VIỆN ĐẠI HỌC Y HÀ NộI
}

\author{
Nguyễn Khang Sơn ${ }^{1}$, Dương Tiến Tùng ${ }^{1}$
}

\section{TÓM TẮT}

Muc tiêu: Đánh giá hiệu quả và tìm hiểu một số yếu tố ảnh hưởng của phương pháp thụ tinh ống nghiêm (IVF/ICSI) sử dụng tinh trùng trích xuất. Phương pháp: Mô tả hồi cứu trên 77 chu kỳ thụ tinh ống nghiệm sử dụng tinh trùng trích xuất (64 trường hợp từ mào tinh và 13 trường hợp từ tinh hoàn), tại Trung tâm Hố trớ sinh sản và Cồng nghể Mô ghép Bệnh viện Đại học Y Hà Nội, giai đoạn 2018-2020. Kết quả: Tỷ lê thu tinh là $77,1 \%$ (trên số noãn ICSI), tỷ lệ có thai là $67,5 \%$ và tỷ lệ trẻ sinh sống là $57,1 \%$ (trên số chu kỳ IVF). Không có sự khác biệt về kết quả khi sử dụng tinh trùng trích xuất từ mào tinh hoặc từ tinh hoàn. Tuổi người chồng và thời gian vô sinh không ảnh hưởng tới tỷ lệ có thai. Kết luận: Thụ tinh ống nghiệm bằng tinh trùng trích xuất là phương pháp điêu trị có hiệu quả cho bệnh nhân vô tinh.

Từ khóa: vô tinh, tinh trùng trích xuất, ICSI, PESA, MESA, TEFNA, TESE.

\section{SUMMARY}

THE OUTCOME OF IN VITRO FERTILIZATION

USING RETRIEVED SPERMS IN HANOI

MEDICAL UNIVERSITY HOSPITAL

Objectives: The aim of this study was to

${ }^{1}$ Trường Đại hoc Y Hà Nội

Chịu trách nhiệm chính: Dương Tiến Tùng

Email: Duongtunghmu@gmail.com

Ngày nhận bài: 19.7.2021

Ngày phản biên khoa hoc: 6.9.2021

Ngày duyệt bài: 20.9.2021 evaluated IVF/ICSI outcome by using retrieved sperms and some influencing factors. Methods: Retrospective descriptive study in 77 IVF cycles used retrieved sperms in Hanoi Medical University Hospital in the period 2018 - 2020. Results: In 77 cases, 64 cases used epididymal sperm and testicular sperm was used in the remaining 13 cases. Fertilization rate, pregnancy rate and live birth rate were $77,1 \%, 67,5 \%$, and $57,1 \%$, respectively. No significant differences were found between the outcomes of patients who used epididymal as well as testicular sperm. Paternal age and duration of infertility have no effect on the pregnancy rate. Conclusion: IVF using retrieved sperms is an efficient method in cases of azoospermia.

Keywords: Azoospermia, retrieved sperm, PESA, MESA, TEFNA, TESE.

\section{I. ĐĂT VẤN ĐỀ}

Vô sinh hiên nay đã trở thành vấn đề thời sự của tất cả các quốc gia trên thế giới. Khoảng $50 \%$ các trường hợp vô sinh có nguyên nhân liên quan đến nam giới, trong đó các trường hợp vô tinh (azoospermia) - không có tinh trùng trong tinh dịch chiếm từ $10-20 \%$ [1].

Tiểm tinh trùng vào bào tương của noãn ICSI (Intracytoplasmic sperm injection) là phương pháp điều trị phố biến cho nam giới vô tinh. Tinh trùng trích xuất từ mào tinh hoặc tinh hoàn bằng nhiêu phương pháp khác nhau như PESA (choc hút mào tinh qua da), TEFNA (choc hút tinh hoàn bằng kim nhỏ), TESE (phẫu thuật 
thu nhận tinh trùng bằng phương pháp xẻ tinh hoàn)... được sử dụng để ICSI với trứng của người vợ đã mang lại nhiều hy vọng cho các cặp vợ chồng vô sinh [1].

Trong những năm vừa qua, thụ tinh ống nghiệm bằng tinh trùng trích xuất đã trở thành phương pháp điều trị thường quy cho các bệnh nhân nam vô tinh tại Trung tâm Hỗ trợ sinh sản và Công nghệ Mô ghép (HTSS\&CNMG), Bệnh viện Đại học Y Hà Nội. Với sự hoàn thiện về kỹ thuật trích xuất tinh trùng, hiệu quả điều trị của phương pháp này ngày càng được nâng cao. Chúng tôi làm nghiên cứu này với mục tiêu đánh giá hiệu quả và tìm hiểu một số yếu tố ảnh hưởng của phương pháp thụ tịnh ông nghiệm sử dụng tinh trùng trích xuất.

\section{II. ĐỐI TƯợNG VÀ PHƯƠNG PHÁP NGHIÊN CỨU}

2.1. Đối tượng nghiên cứu. Các cặp vợ chồng vô sinh do không có tinh trùng trong tinh dịch (vô tinh) thực hiện thụ tinh trong ống nghiệm tại Trung tâm Hố trợ sinh sản và Công nghệ Mô ghép, Bệnh viện Đại học Y Hà Nội từ tháng $1 / 2018$ đến tháng 12/2020.

*Tiêu chuẩn lứa chọn: người chồng vô tinh được thực hiện thủ thuật trích xuất tinh trùng từ mào tinh hoặc tinh hoàn bằng một trong các phương pháp: PESA, MESA, TEFNA hoặc TESE. Tinh trùng trích xuất được sử dụng làm ICSI tại Trung tâm Hỗ trợ sinh sản và Công nghệ mô ghép.

*Tiêu chuẩn loại trừ: các trường hợp thụ tinh ống nghiệm bằng tinh trùng trích xuất nhưng chưa chuyển phôi.

\subsection{Phương pháp nghiên cứu}

*Thiết kế nghiên cứu: mô tả hồi cứu.

*Các bước nghiên cứu:

- Các cặp vợ chồng vô sinh do chồng không có tinh trùng trong tinh dịch được khám và làm các xét nghiệm cần thiết.

- Chỉ định làm thụ tinh ống nghiệm bằng tinh trùng trích xuất.

- Kích thích buồng trứng cho người vợ theo phác đồ $\mathrm{GnRH}$ antagonist.

- Thực hiện chọc hút noãn, trích xuất tinh trùng từ mào tinh (PESA, MESA), nếu không có tinh trùng di động thì chuyển sang trích xuất tinh trùng từ tinh hoàn (TEFNA, TESA, TESE).

- ICSI noãn bằng tinh trùng trích xuất, phôi được nuôi cấy theo quy trình của trung tâm HTSS\&CNMG, Bệnh viện Đại học Y Hà Nội.

- Chuyển phôi tươi hoặc chuyển phôi đồng lạnh.

- Theo dõi sau chuyển phôi bằng xét nghiệm BhCG và siêu âm.

\section{* Các biến số nghiên cứu:}

- Tuổi vợ, tuổi chồng, số năm vô sinh, vị trí trích xuất tinh trùng.

- Chất lượng tinh trùng trích xuất, số noãn chọc hút, chẩt lượng noãn.

- Tỷ lệ thụ tinh tính bằng số noãn thụ tinh trên tổng số noãn được ICSI, tỷ lệ tạo phổi tính bằng số phôi tạo thành trên tổng số noãn ICSI, tỷ lệ phôi tốt tính bằng tổng số phôi độ I và độ II theo đồng thuận Alpha (2010) trên tổng số phôi.

- Tỷ lệ có thai tính bằng số chu kỳ có nồng độ ßhCG tại thời điểm 14 ngày sau chuyển phôi $>$ $25 \mathrm{IU} / \mathrm{L}$ trên tổng số chu kỳ chọc trứng, tỳ lệ trẻ sinh sống tính bằng số chu kỳ có trẻ sinh sống trên số chu kỳ chọc trứng.

* Xử lý số liệu: Số liệu được thu thập và xử lý bằng phần mểm SPSS 22.0, dùng phép toán thống kê mô tả cho các biến định tính và định lượng, so sánh các giá trị trung bình $\mathrm{T}$ test và so sánh tỷ lệ bằng Fisher's Exact Test.

* Đạo đức trong nghiên cứu: Nghiên cứu thuộc loại mô tả hồi cứu, không can thiệp trên bệnh nhân và được sự cho phép của lãnh đạo Trung tâm HTSS\&CNMG, Bệnh viện Đại học Y Hà Nội. Thông tin bệnh nhân được mã hoá, giữ bí mật và chỉ phục vụ cho mục đích nghiên cứu.

\section{KẾT QUẢ NGHIÊN CỨU}

\section{1. Đặc điểm că̆p vợ chồng và chất lượng tinh trùng trích xuất}

Bảng 1. Đặc điểm cặp vợ chồng vô sinh và mẫu tinh trùng trích xuất

\begin{tabular}{|c|c|c|c|}
\hline Đặc điểm & $\begin{array}{c}\text { Tinh trùng từ mào tinh } \\
(\mathbf{n = 6 4 )}\end{array}$ & $\begin{array}{c}\text { Tinh trùng từ tinh } \\
\text { hoàn }(\mathbf{n}=\mathbf{1 3})\end{array}$ & $\mathbf{p}$ \\
\hline Tuối chồng (năm) & $33,84 \pm 6,65$ & $34,85 \pm 6,10$ & 0,846 \\
\hline Tuô̂i vợ (năm) & $29,92 \pm 4,88$ & $30,92 \pm 5,71$ & 0,468 \\
\hline Thời gian vồ sinh (năm) & $3,78 \pm 3,26$ & $4,77 \pm 2,71$ & 0,749 \\
\hline Số mấu có tinh trùng di động (\%) & $64(100)$ & $8(61,5)$ & $\mathbf{0 , 0 0 1}$ \\
\hline $\begin{array}{c}\text { Số mấu có tinh trùng hình thái bình } \\
\text { thường (\%) }\end{array}$ & $26(40,6)$ & $3(23,1)$ & $\mathbf{0 , 0 3 0}$ \\
\hline
\end{tabular}

Nhận xét: Trong giai đoạn 3 năm, từ tháng 1/2018 đến tháng 12/2020 tại Trung tâm Hô̂ trợ sinh sản và Công nghệ Mô ghép có 77 cặp vợ

chông đáp ứng đủ tiêu chuấn được đưa vào nghiên cứu, trong đó có 64 trường hợp (chiếm $83,1 \%$ ) thu nhận được tinh trùng di động tại 
mào tinh, 13 trường hợp $(16,9 \%)$ phải chuyển sang trích xuất tinh trừng từ tinh hoàn. Trong các trường hợp trích xuất tinh trùng từ tinh hoàn, có 8 trường hợp thu được tinh trùng di động tại thời điểm chọc hút (chiếm 61,5\%).

Các đặc điểm về tuổi chồng, tuổi vợ và thời gian vô sinh là tương đương giứa các nhóm, sự khác biệt không có ý nghĩa thống kê, với $p$ > 0,05 . Tỷ lệ mẫu tinh trùng có hình thái bình thường ở nhóm tinh trùng từ mào tinh $(40,6 \%)$ cao hơn nhóm tinh trùng trích xuất từ tinh hoàn $(23,1 \%)$, sự khác biệt này có ý nghĩa thống kê với $p<0,05$.

\subsection{Kết quả thụ tinh ống nghiệm bằng tinh trùng trích xuất}

Bảng 2. Kết quả điều trị thụ tỉnh ống nghiệm bằng tinh trùng trích xuất

\begin{tabular}{|c|c|c|c|}
\hline Chỉ số & $\begin{array}{l}\text { Tinh trùng từ mào } \\
\text { tinh }(n=64)\end{array}$ & $\begin{array}{l}\text { Tinh trùng từ tinh } \\
\text { hoàn }(\mathbf{n}=13)\end{array}$ & Tổng \\
\hline Tống số noãn & 912 & 195 & 1107 \\
\hline Số noãn chọc hút trung bình $\left({ }^{x} \pm S D\right)$ & $14,25 \pm 7,65$ & $15,00 \pm 8,61$ & $14,40 \pm 7,80$ \\
\hline Tý lệ thụ tinh (\%) & 76,7 & 79.6 & 77,1 \\
\hline Tỷ lệ tạo phôi (\%) & 75,6 & 77,4 & 75,9 \\
\hline Tý lề phôi tốt (\%) & 79,0 & 81,1 & 79,3 \\
\hline Tý lệ có thai (\%) & 68,8 & 61,5 & 67,5 \\
\hline Tỷ lệ làm tố (\%) & 41,8 & 38,7 & 41,2 \\
\hline Tỷ lệ trẻ sinh sống (\%) & 57,8 & 53,8 & 57,1 \\
\hline
\end{tabular}

Nhận xét: Số noãn chọc hút trung bình, tỷ lẹ thụ tinh, tỷ lệ tạo phôi và tỷ lệ phôi tốt là tương đương giữa nhóm tinh trùng trích xuất từ mào tinh và từ tinh hoàn. Tỷ lệ có thai, tỷ lệ làm tổ và tỷ lệ có trẻ sinh sống ở nhóm tinh trùng trích xuất từ mào tinh có xu hướng cao hơn so với nhóm tinh trùng trích xuất từ tinh hoàn, tuy nhiên sự khác biệt không có ý nghĩa thống kê $(p>0,05)$.

3.3. Một số yếu tố ảnh hưởng tới kết quả thụ tinh ống nghiệm bằng tinh trùng trích xuất

Bảng 3. Mốt số yếu tố ảnh hưởng tới kêt quả có thai

\begin{tabular}{|c|c|c|c|}
\hline Chì số & Có thai & Không có thai & p \\
\hline Tuối chồng (năm) & $33,00 \pm 5,82$ & $36,12 \pm 7,49$ & 0,781 \\
\hline Thời gian vô sinh (năm) & $3,78 \pm 3,26$ & $4,77 \pm 2,71$ & 0,749 \\
\hline $\begin{array}{c}\text { Số phôi tô̂́t được chuyển } \\
(\bar{x} \pm \text { SD) }\end{array}$ & $1,62 \pm 0,66$ & $1,32 \pm 1,03$ & $\mathbf{0 , 0 1 0}$ \\
\hline
\end{tabular}

Nhận xét: Không có sự khác biệt về tuổi người chồng giữa nhóm có thai và không có thai. Thời gian vố sinh của nhóm có thai $(3,78 \pm 3,26$ năm) nhỏ hơn nhóm không có thai $(4,77 \pm 2,71$ năm), nhưng không có ý nghĩa thống kê $(p>0,05)$. Số phôi tốt được chuyển (phôi độ I và độ II) trung bình của nhóm có thai cao hơn nhóm không có thai, sự khác biệt này là có ý nghĩa thông kê với $p<0,05$.

\section{BÀN LUÂ̂N}

*Bàn luận về đặc điểm mẫu tinh trùng trích xuất. Tỷ lệ mấu tinh trùng có hình thái bình thường khi trích xuất từ mào tinh cao hơn nhóm trích xuất từ tinh hoàn. Điều này là do tinh trùng trong ống sinh tinh của tinh hoàn thường là chưa trưởng thành; chúng thường có các giọt bào tương vùng cổ. Trong quá trình di chuyển đến mào tinh, tinh trùng tiếp tục hoàn thiện về hình thái.

Có 64/77 trường hợp thu được tinh trùng di động từ chọc hút mào tinh hoàn (bao gồm cả mẫu tươi và mấu sau rã đông), chiếm $83,1 \%$. Tỷ lệ này là tương đương với nghiên cứu của Glina S và cộng sự (2003) là $82 \%$ [2]. Điều này là do trong quá trình di chuyển từ các ống sinh tinh ra mào tinh, tinh trùng đã được hoàn thiện về cấu trúc và chức năng. Ngoài ra các mấu tinh trùng trích xuất khi đã đủ điêu kiện trữ đông thường là những mẫu chất lượng tốt nên có tỷ lệ di động cao sau rã đông. Trong các tài liệu kinh điển có cho rằng tinh trùng ở tinh hoàn là tinh trùng không có khả năng di động. Tuy nhiên trong nghiên cứu này chúng tôi quan sát thấy tinh trùng tại tinh hoàn vẫn có khả năng di động tại chỗ hoặc di động chậm (loại $B$ và $C$, theo WHO 2021) (Bảng 1). Đối với các mẫu tinh trùng di động rất kém nên được nuôi cấy thêm ở $37^{\circ} \mathrm{C}$ trong ít nhất 2 giờ trước ICSI để cải thiện khả năng di động của tinh trùng. Trong nghiển cứu của chúng tôi, cả 5 trường hợp không có tinh trùng di động tại thời điểm trích xuất sau khi nuôi cấy đều có tinh trùng di động để ICSI. Trong trường hợp nếu không tìm thấy tinh trùng di động, chuyên viên phôi học của Trung tâm vẫn có thể lựa chon tinh trùng sống từ các tinh trùng bất động để ICSI bằng các kỹ thuật mới như HOST (Hypo-osmotic swelling test) hoăc LAISS (Laser assisted immotile sperm selection). 
*Bàn luận về kết quả thụ tinh ống nghiệm bằng tinh trùng trích xuất. Với 77 chu kỳ thụ tinh ống nghiệm, số noãn chọc hút được là 1107 noãn, số noã̃n trung bình là 14,40 $\pm 7,80$ noãn/chu kỳ (Bảng 2), đây là số lượng noãn lý tưởng cho một chu kỳ thụ tinh ống nghiệm. Số noãn này cao hơn nghiên cứu của Hồ Sỹ Hùng (2013) với 8,62 \pm 4,3 noãn/chu kỳ [3]. Có được sự thay đổi này có thể do sự thay đổi về phác đồ kích thích buồng trứng từ $\mathrm{GnRH}$ agonist sang phác đồ $\mathrm{GnRH}$ antagonist.

Tỷ lệ thụ tinh và tỷ lệ tạo phôi lần lượt là $77,1 \%$ và $75,9 \%$, điều này cho thấy rằng tỉ lệ thụ tinh là khá cao và đa số noãn đã thụ tinh đều phát triển thành phôi. Kết quả này cao hơn tác giả Kamal (tỷ lệ tương ứng là $68,0 \%$ và $64,2 \%$ ) và tương đương với nghiên cứu của Trịnh Thị Ngọc Yến (tỷ lệ thụ tinh là 78,9\%) [4]. Tỷ lệ phôi tốt (phôi độ I và độ II) ở nhóm tinh trùng trích xuất từ mào tinh $(79,0 \%)$ và từ tinh hoàn $(81,1 \%)$ là tương đương nhau. So với nghiên cứu của Trịnh Thị Ngọc Yến trong giai đoạn 2015 - 2017 thì tỷ lệ thụ tinh không có sự khác biệt $(78,9 \%$ và $77,1 \%)$ nhưng tỷ lệ phôi tốt trong nghiên cứu của chúng tôi cao hơn đáng kể (80,0\% so với $62,6 \%)$. Có được điều này có thể là do sự phát triển không ngừng về tay nghề và qui trình kỹ thuật của các chuyên viên phôi học cũng như sự nâng cấp về trang thiết bị của trung tâm.

Tỷ lệ có thai, tỷ lệ làm tổ và tỷ lệ trẻ sinh sống của nhóm tinh trùng trích xuất từ mào tinh (tương ứng là $68,8 \%, 41,8 \%$ và $57,8 \%$ ) có xu hướng cao hơn nhóm tinh trùng trích xuất từ tinh hoàn (tương ứng là $61,5 \%, 38,7 \%$ và $53,8 \%)$, tuy nhiên sự khác biệt này không có ý nghĩa thống kê (Bảng 2). Tỷ lệ có thai trong nghiên cứu của chúng tôi cao hơn nghiên cứu của tác giả Hồ Sỹ Hùng $(36,8 \%)$. Điều này có thể do sự khác biệt về phác đồ điều trị và chất lượng labo giữa các trung tâm IVF.

Có thể thấy rằng dường như nguồn gốc tinh trùng không ảnh hưởng rõ rệt tới chất lượng phôi cũng như tỷ lệ có thai ở bệnh nhân vô tỉnh. Nhận định này là tương đồng với nghiên cứu tổng quan hệ thống của Shih (2019) [5]. Trong nghiên cứu của Shih và cộng sự, dữ liệu được lấy từ 8 nghiên cứu trước đó, với 2060 chu kỳ IVF/ICSI. Kết quả cho thây không có sự khác biệt về tỷ lệ làm tổ, tỷ lệ có thai giữa nhóm tinh trù̀ng trích xuất từ mào tinh và tinh hoàn ở bệnh nhân vô tinh. Một nghiên cứu khác của Choudhary A (2013) còn cho thây tỷ lệ thụ tinh, tỷ lệ làm tổ và tỷ lệ có thai là không có sự khác biệt giữa nhóm tinh trùng trích xuất và tinh trùng xuất tinh [6]. Điều này mở ra một hướng đi mới cho những bệnh nhân mà tinh trùng có tỷ lệ DNA phân mảnh cao có thể xem xét việc sử dụng tinh trùng trích xuất để làm thụ tinh ống nghiệm nhằm thu được tinh trùng có chất lượng DNA tốt hơn. Lợi ích của phương pháp này đã được phân tích trong nghiên cứu của Esteves và cộng sự (2018) [7].

*Bàn luận về một số yếu tố ảnh hưởng tới kết quả. Theo nghiên cứu của Aboulghar $M$ và cộng sự (2007) thì tuổi chồng và thời gian vô sinh có thể ảnh hưởng tới kết quả thụ tinh nhưng không ảnh hưởng tới kết quả có thai [8]. Trong nghiên cứu này, tuy rằng nhóm không có thai có tuổi người chồng và số năm vô sinh trung bình lớn hơn nhóm không có thai nhưng không có mối liên quan giữa hai thông số này và tỷ lệ có thai với $p>0,05$.

Ta cũng thây rằng tỷ lệ thai lâm sàng liên hệ chặt chẽ với số lượng và chất lượng phôi ở mối lần chuyển phôi. Trong nghiên cứu này, số phôi tốt được chuyển trung bình của nhóm có thai (1,62 \pm 0,66 phôi) lớn hơn nhóm không có thai $(1,32 \pm 1,03$ phôi), và sự khác biệt này là có ý nghĩa thống kê $\mathrm{p}<0,05$. Dường như, chuyển phôi với số lượng phôi tốt nhiều hơn thì khả năng có thai của cặp vợ chồng vô tinh sẽ tăng lên. Tuy nhiên việc tăng số lượng phôi tốt khi chuyển phôi ảnh hưởng như thể nào tới tỷ lệ đa thai, sinh non thì cần được làm rõ trong các nghiên cứu tiếp theo.

\section{KẾT LUẬN}

Thụ tinh trong ống nghiệm sử dụng tinh trùng trích xuất là phương pháp điều trị hiệu quả cho các bệnh nhân nam vô tinh với tỳ lệ thụ tinh là $77,1 \%$, tỷ lệ có thai là $67,5 \%$ và tỷ lệ trẻ sinh sống là $57,1 \%$. Không có sự khác biệt vể tỷ lệ thụ tinh, tỷ lệ có thai giữa nhóm sử dụng tinh trùng trích xuất từ mào tinh và nhóm trích xuất từ tinh hoàn. Tỷ lệ có thai không liên quan tới tuổi người chồng và số năm vô sinh nhưng có liên quan đến số lượng phôi tốt ở mối lần chuyển phôi.

\section{Lời cảm ơn và lời cam kết}

- Các tác giả xin trân trọng cảm ơn các cán bộ, nhân viên tại Trung tâm Hố trợ sinh sản và Cồng nghệ Mô ghép, Bệnh viện Đại học Y Hà Nội đã tạo điều kiện cho chúng tôi thực hiện nghiên cứu này.

- Các tác giả xin cam kết không có tranh chấp về quyền lợi.

\section{TÀI LIẸU THAM KHẢO}

1. Gudeloglu A, Parekattil SJ (2013). Update in the evaluation of the azoospermic male. Clinics 
(Sao Paulo). 68 Suppl 1:27-34.

2. Glina S, Fragoso JB, Martins FG, Soares JB, Galuppo AG, Wonchockier $R$ (2003). Percutaneous epididymal sperm aspiration (PESA) in men with obstructive azoospermia. Int Braz J Urol. 29(2):141-145; discussion 145-146.

3. Hồ Sỹ Hùng, Trân Thi Phương Mai (2013). Kết quả và các yế tố ảnh hưởng đến kỹ thuật tiêm tinh trùng vào bào tương noãn bằng tinh trùng lấy từ mào tinh. Tap chí Phu Sản. 11(2):139-142.

4. Trịnh Thi Ngọc Yến, Nguyến Mạnh Hà (2018). Đánh giá kết quả tiêm tinh trùng trích xuất vào bào tương noãn tại Bệnh viện Đại Học Y Hà Nội. Y hoc Viêt Nam. 471:114-118.

5. Shih K-W, Shen P-Y, Wu C-C,Kang Y-N
(2019). Testicular versus percutaneous epididymal sperm aspiration for patients with obstructive azoospermia: a systematic review and meta-analysis. Translational Andrology and Urology. 8(6):63140-63640.

6. Choudhary A (2013). Comparision of Intracytoplasmic Sperm Injection Outcomes Using Ejaculated Sperm and Retrieved Sperm. 4(6):3.

7. Esteves (2018). Use of testicular sperm for intracytoplasmic sperm injection in men with high sperm DNA fragmentation: a SWOT analysis.

8. Aboulghar $M$, Mansour $R$, Al-Inany $H$, et al (2007). Paternal age and outcome of intracytoplasmic sperm injection. Reprod Biomed Online. 14(5):588-592.

\section{NHẬN XÉT KẾT QUẢ ĐIỀU TRỊ NGộ ĐộC CHÌ CẤP Ở TRẺ EM DO DÙNG “THUỐC CAM"}

\section{Đinh Thị Hồng*, Lê Ngọc Duy*, Trương Thị Mai Hồng*}

\section{TÓM TẮT}

Mục tiêu: Nghiên cứu một số đặc điểm lâm sàng, cân lẩm sàng và đánh giá hiêu quả điều trị ngô độc chì ở trẻ em do sử dụng "thuốc cam". Đối tượng và phương pháp nghiên cứu: mô tả, cắt ngang trên 89 trẻ, tại Bệnh viện Nhi Trung ương, trong thời gian từ $6 / 2012$ đển $6 / 2021$. Kết quả: $60,7 \%$ trẻ dưới 1 tuổi; $47,2 \%$ trẻ được bôi vì tưa miêng. Triêu chứng lâm sàng: thay đổi tri giác $(40,4 \%)$, co giật $(48,3 \%)$, da xanh $(82 \%)$, nôn $(61,8 \%)$, tiêu chảy $(29,2 \%)$. Cận lâm sàng: $80 \%$ xquang có tăng cản quang đầu xương dài; giãn não thất $9,4 \%$; xuất hiên sóng đônng kinh trên điện não đồ $19,4 \%$. Dịch não tủy biến đổi với protein tăng cao $(1,64 \pm 1,36 \mathrm{~g} / \mathrm{l})$ trong khi tế bào bình thường hoăc tăng nhẹ $(9,8 \pm 24,89$ bạch cầu). Nồng độ chì máu trung bình lúc nhâp viện 108,39 \pm $55,8 \mu \mathrm{g} / \mathrm{dl}$. Sau 30 ngày điều trị nồng độ chì máu giảm $49,7 \%$, sau 1 năm giảm $71,3 \%$ và chì niêu đã tăng thải nhanh tại $T_{5}$ và $T_{30}$ với giá trị cao nhất là $5,664 \mathrm{mg} / \mathrm{l}$. Tỷ lệ tử vong là $6 / 89$ trẻ $(6,7 \%)$. Kết luận: Biểu hiện lẩm sàng của ngộ độc chì thường gặp là co giật, thay đổi tri giác và thiểu máu. Biến đối dịch não tủy theo kiểu protein tăng, tế bào bình thường. Nồng độ chì máu giảm dần và chì niệu tăng dần trong quá trình điều trị. Tỷ lệ tử vong là $6,7 \%$

Tư khóa: ngộ độc chì, thuốc cam.

\section{SUMMARY}

THE OUTCOMES OF MANAGEMENT OF ACUTE LEAD POISONING IN CHILDREN USING TRADITIONAL MEDICINE

Objectives: To investigate the clinical, sub-clinical

*Bệnh viện Nhi Trung ương

Chịu trách nhiêm chính: Đinh Thị Hồng

Email: dr.hong2909@gmail.com

Ngày nhận bài: 20.7.2021

Ngày phản biện khoa học: 8.9.2021

Ngày duyệt bài: 21.9.2021 features and the outcomes of management of acute lead poisoning in children using traditional medicine. Subjects and method: A descriptive cross sectional study to assess 89 patients in the NHP from June 2012 to June 2021 . Results: $60,7 \%$ of the participants are under 12 months old. $47,2 \%$ patients used traditional medicine for the treatment of fungi infection in the mouth. Common clinical features include mental status change $(40,4 \%)$, seizures $(48,3 \%)$, skin pallor $(82 \%)$ vomiting $(61,8 \%)$ and diarrhea $(29,2 \%)$. Sub-clinical features include: $80 \%$ of participants had increased mineral density of epiphysis, enlarge of ventricle $(9,4 \%) ; \quad 19,4 \%$ with epileptic waves in electroencephalogram. CSF changes in which protein elevates $(1,64 \pm 1,36 \mathrm{~g} / \mathrm{l})$ and cells were normal or mild increased $(9,8 \pm 24,89)$. The mean blood lead levels on admission is $108,39 \pm 55,8 \mu \mathrm{g} / \mathrm{dl}$. After 30 day of treatment, the blood lead levels decreased dramatically to $49,7 \%$ and to $71,3 \%$ after 1 year of treatment. Urine lead levels increased in day 5 and day 30 with the peak of $5,644 \mathrm{mg} / \mathrm{l}$. The mortality rate was of $6,7 \%$ (6/89 patients). Conclusion: Clinical presentation of children with lead poisoning included seizures and mental alternatives and anaemic. In the cerebrospinal fluid, proteins elevated but cells were unchanged. The blood lead levels decrease dramatically and urine lead levels gradually increased during treatment. The mortality rate was of $6,7 \%$

Keywords. lead poisoning, traditional medicine.

\section{I. ĐẶT VẤN ĐỀ}

Theo định nghĩa của Hiệp hội nhi khoa Hoa Kỳ, ngộ độc chì khi nồng độ chì trong máu(BLLBlood lead level) $\geq 10 \mu \mathrm{g} / \mathrm{dl}[1]$,[2]. Hội chứng não cấp như nôn, thay đổi hành vi, mất điều hòa, co giật, hôn mê thường chỉ xuất hiện trong ngộ độc chì nặng với $B L L \geq 70 \mu \mathrm{g} / \mathrm{dl}$ [3]. Hiện nay, người dân vẫn thường sử dụng "thuốc cam" không rõ nguồn gốc để chữa một số bênh của trẻ em như tưa lưỡi, loét miệng, tiêu chảy, biếng ăn do đó 